\title{
Comparative Studies between an Artificial Diet and Ephestia kuhniella Zeller Eggs on the Biological Aspects of Coccinella undecimpunctata L. at Three Different Temperatures \\ Hala A. El-Serafi; A. A. Ghanim ; S. S. Awadalla and Mona M. Shalaby \\ Economic Entomology Department, Faculty of Agriculture, Mansoura University, Egypt.
}

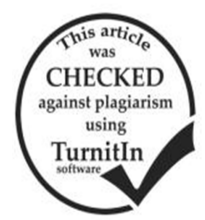

\section{ABSTRACT}

The objective of the present investigation was to evaluate rearing of Coccinella undecimpunctata $\mathrm{L}$. on an artificial diet and Ephestia kuhniella eggs. Significant differences were observed between the artificial diet and E. kuhniella eggs on the incubation period and the total immature stages duration at the three tested temperatures. The life cycle of $C$. undecimpunctata was the shortest when reared on the artificial diet and E. kuhniella eggs at $30 \pm 1^{\circ} \mathrm{c}$ and $65 \pm 5 \%$ R.H. and lasted $27.5 \pm 0.15$ and $22.7 \pm 0.20$ days, respectively. The total larval survival rate was the highest for C. undecimpunctata when reared on E. kuhniella and recorded $86.67 \%, 96.67 \%$ and $90 \%$ at the three different temperatures. The longest female and male longevity were observed when reared at $20 \pm 1{ }^{\circ} \mathrm{C}$ on two diets. The high fecundity value was found at $25 \pm 1{ }^{\circ} \mathrm{C}$ for two diets followed by $30 \pm 1{ }^{\circ} \mathrm{C}$. While, it was lowest at $20 \pm 1{ }^{\circ} \mathrm{C}$ for $\mathrm{C}$. undecimpunctata.

Keywords: Coccinella undecimpunctata L. , artificial diet and Ephestia kuhniella.

\section{INTRODUCTION}

Biological control is one of the beneficial actions in managing pests and their damage. It is defined as the reduction of pest population by natural enemies. This biological control agents, which called "natural enemies", is especially important for reducing the numbers of pest insects and mites (Dreistadt and Statewide 2014).

The eleven-spotted ladybird, Coccinella undecimpunctata L. (Coleoptera : coccinellidae ) is an important polyphagous predator and use in the biological control for a large wide of pests such as aphids, eggs and new hatching of lepidopterian insects and it can be found in different parts of the world with different environmental conditions (Hodek and Honêk 2012). C. undecimpunctata $\mathrm{L}$. is one of the most intensively studied predators because of its importance as biocontrol agent, wide geographical distribution and the diversity of their feeding habits. Because of the sharp reduction on the number of natural preys on some times of the year that's required for the predator mass rearing $C$. undecimpunctata. So, it was important to study some factitious preys or artificial diets. (El-Heneidy et al., 2008 and Song and Swinton 2009).

There are two approaches for developing artificial diets for living organisms. The complicated methods are to prepare a mixture of chemically defined substances (holidic), and the easier technique by mixing natural substances (meridic diets) (Okada, 1970 ; Chen and Qin 1982 ; Hattingh and Samways, 1993 ; Abd El-Salam, 1995 ; Ghanim and ElAdl 1996 and 1997 ; Ghanim et al. 2000 ; Mohamed, 2001 ; El- Serafi, et al. 2002 and Bahy El-Din, 2014).

Temperature is one of the most important environmental factors has effects on the biological aspects of the predators such the developmental duration, ovipositional periods and reproductive ability. The knowledge of environmental factors that can affect the increase in the insect populations is crucial for predicting potential changes in population dynamics and developing sustainable an environment-friendly pest control strategies. (Ghanim and El-Adl, 1987; El-Serafi, 2002 ; Mohamed, 2013 ; Bahy ElDin, 2014 ; Bayoumy, et al. 2015 ; El-Batran, 2015 and Said, 2018). The objective of this study to compare effects of artificial diet and E. kuhniella on the biological aspects of $C$. undecimpunctata at three different temperatures.

\section{MATERIALS AND METHODS}

The present investigation was carried out at the laboratory of the department of Entomology, Faculty of
Agriculture, Mansoura University. Coccinella undecimpunctata adults were collected from guava and peach trees on the Faculty of Agriculture farm, Mansoura University and reared in the laboratory at $25 \pm 1^{\circ} \mathrm{C}$ and $60 \pm$ $5 \%$ relative humidity $(\mathrm{RH})$.

Frozen eggs of Ephestia khuniella (Pyralidae: Lepidoptera) were brought from the Natural Enemies lab, Faculty of Agriculture, Cairo University.

Thirty freshly hatched larvae $(<24 \mathrm{~h}-$ old $)$ as replicates were collected and placed individually in a Petridish (10 cm in diameter) and placed in controlled incubators at $20,25,30^{\circ} \mathrm{C}$ with $60 \pm 5 \% \mathrm{RH}$ and every day fed with artificial diet and E. kuhniella eggs for each temperature. The duration of each larval instar and the number of surviving larvae were recorded and then when larvae were in the pupae stage the duration of pupae stage were recorded. The gender of adults was recorded for each diet on each temperature. After three days of emerging the females and males were collected for copulation. Each pair was placed in a Petri-dish and in the next day every pair were separated in two petri dish to record the longevity of males and the ovipositional periods and fecundity of females.

2. Statistical analysis:-

Data for developmental duration of the immature stages, survival percentage, longevity and fecundity of $C$. undecimpunctata were analyzed by one-way ANOVA, and the means were separated using Student- Newman-Keuls Test by using Costat Software, (2004).

Table1. Artificial diet ingredients used to rear predator, Coccinella undecimpunctata in the laboratory.

\begin{tabular}{lc}
\hline Ingredients & Amounts (g) \\
\hline 1- Sucrose & 56 \\
2- Bee Honey & 10 \\
3- Royal jelly & 5 \\
4- Pollen grains & 9 \\
5- Water & 4 \\
6- Yeast & 2.5 \\
7- Dry milk & 8 \\
8- Dry aphid & 3.5 \\
9- Streptomycin & 2.0 \\
\hline
\end{tabular}

\section{RESULTS AND DISCUSSION}

\section{1- Duration of immature stages:-}

Data illustrated in Table (2) showed significant differences on the incubation period for the artificial diet (f $2,87=98.67$ and $\mathrm{p}=0.0000^{* * *}$ ) and for Ephestia kuhniella eggs $\left(f_{2,87}=139.90\right.$ and $\left.p=0.0000^{* * *}\right)$ between the tested 
temperature for each diet. On the other hand, there were not significant differences between the two diets with the same temperature at $20^{\circ} \mathrm{C}\left(\mathrm{f}_{1,58}=0.23\right.$ and $\mathrm{p}=0.6339 \mathrm{~ns}$, respectively), at $25^{\circ} \mathrm{C}\left(\mathrm{f}_{1,58}=0\right.$ and $\left.\mathrm{p}=1 \mathrm{~ns}\right)$ and at $30^{\circ} \mathrm{C}(\mathrm{f}$ $2,87=2.43$ and $\mathrm{p}=0.1246)$. Temperature shortened the incubation period similar effect of temperature. Recorded by Ramesh Babu and Azam, (1987) and Abdel-Salam et al.(2018).

The longest incubation period for the eleven spotted ladybird C. undecimpunctata were at $20 \pm 1^{\circ} \mathrm{C}$ for the artificial diet and E.kuhniella eggs and represented by $6.5 \pm$ $0.10,6.6 \pm 0.09$ days, respectively. While, the shortest incubation period were at $30 \pm 1{ }^{\circ} \mathrm{C}$ and $65 \pm 5 \% \mathrm{RH}$ and presented by when reared on the artificial diet and E.kuhniella eggs $4.6 \pm 0.09$ and $4.4 \pm 0.09$ days respectively. The reduction of the incubation period may be due to the elevated of the embryonic development rate at the higher temperature. These results in consistent with those of Srivastava and Omkar (2003).

Data in Table (2) showed that there were significant differences between the three temperature degrees studied for each diet in the total larval stages when E. kuhniella eggs (f $2.81=310.95$ and $\left.\mathrm{p}=0.0000^{* * *}\right)$ and the artificial diet $\left(\mathrm{f}_{2,68}=\right.$ 337.61 and $\left.\mathrm{p}=0.0000^{* * *}\right)$, pupal stage when E. kuhniella eggs $\left(\mathrm{f}_{2,79}=135.39\right.$ and $\left.\mathrm{p}=0.0000^{* * *}\right)$ and the artificial diet (f ${ }_{2,68}=238.61$ and $\mathrm{p}=0.0000^{* * *}$ ). And total immature stages when E. kuhniella eggs (f ${ }_{2,79}=575.95$ and $\mathrm{p}=$ $\left.0.0000^{* * *}\right)$ and for the artificial diet $\left(\mathrm{f}_{2,63}=591.51\right.$ and $\mathrm{p}=$ $0.0000 * * *$ ). But there were significant differences with the artificial diet and E. kuhniella eggs for the total larval stage at $20 \pm 1^{\circ} \mathrm{C},\left(\mathrm{f}_{2,81}=310.95\right.$ and $\left.\mathrm{p}=0.0000^{* * *}\right)$, at $25 \pm 1^{\circ} \mathrm{C}\left(\mathrm{f}_{2,}\right.$ ${ }_{68}=337.51$ and $\left.\mathrm{p}=0.0000^{* * *}\right)$ and at $30 \pm 1^{\circ} \mathrm{C}\left(\mathrm{f}_{2,68}=337.51\right.$ and $\left.\mathrm{p}=0.0000^{* * *}\right)$. Significant differences were showed in the pupal stage between artificial diets and E. kuhniella eggs at $30 \pm 1{ }^{\circ} \mathrm{C}\left(\mathrm{f}_{2,72}=7.46\right.$ and $\left.\mathrm{p}=0.0011^{* *}\right)$ and at $25 \pm 1^{\circ} \mathrm{C}$ (f $2,78=2.57$ and $\mathrm{p}=0.0830 \mathrm{~ns})$, while, it was not significant at $20 \pm 1^{\circ} \mathrm{C}$ ( $\mathrm{f}_{2,73}=2.88$ and $\mathrm{p}=0.0625 \mathrm{~ns}$ ) for the three different diets. Because of the increasing of temperature increased the metabolism of larvae voracity this leads to increasing the supply of the nutrients and resulting rapid development according to Ponsonby and Copland (1996) and Srivastava and Omkar (2003).

On the other hand there were significant differences between the artificial diet and E. kuhniella eggs on the total immature stages duration at the three tested temperatures when E. kuhniella eggs ( $\mathrm{f}_{2,81}=310.95$ and $\mathrm{p}=0.0000^{* * *}$ ) and for the artificial diet ( $\mathrm{f}_{2,68}=337.51$ and $\mathrm{p}=0.0000^{* * *}$ ). And there was significant variation at the three different temperatures at $20 \pm 1{ }^{\circ} \mathrm{C}\left(\mathrm{f}_{1,50}=220.92\right.$ and $\left.\mathrm{p}=0.0000 * * *\right)$, at $25 \pm 1^{\circ} \mathrm{C}$ ( $\mathrm{f}_{1,51}=1094.62$ and $\mathrm{p}=0.0000^{* * *}$ ) and at $30 \pm 1^{\circ} \mathrm{C}\left(\mathrm{f}_{1,48}=316.74\right.$ and $\left.\mathrm{p}=0.0000^{* * *}\right)$. The total larval duration, the pupal stage and total immature stages a $\mathrm{t} 30$ $\pm 1^{\circ} \mathrm{C}$ and $65 \pm 5 \% \mathrm{RH}$ were the shortest when this predator reared on E. kuhniella eggs and represented by $13.5 \pm 0.17$, $4.7 \pm 0.09$ and $22.7 \pm 0.20$ days, respectively. Meanwhile, there were the longest when reared on the artificial diet and recorded $22.9 \pm 0.16,7.4 \pm 0.11$ and $36.7 \pm 0.19$ days, respectively.

Bahy El-Din (2014) recorded that the total larval period of $C$. undecimpunctata lasted $15.97 ; 18.11 ; 12.85$; 14.02 and 11.98 days on four artificial diets and A. gossypii under constant temperature of $27 \pm 2^{\circ} \mathrm{C}$. He added that averages of mean number of deposited eggs by $C$. undecimpunctata were $204.15 ; 124.69 ; 518.35 ; 262.76$ and $761.75 \mathrm{eggs} /$ female when the predator fed on the four artificial diets tested and $A$. gossypii, respectively. Said (2018) noticed that the developmental times of $\mathrm{C}$. indecimpunctata preyed aphids reared on three eggplant varieties were decreased with increasing the temperature, whereas the developmental rates at $30 \pm 1^{\circ} \mathrm{C}$. These results in consistent with those of Ghanim and El-Adl (1987); El- Serafi, et al. (2002); Mohamed, (2013); Bayoumy et al. (2015) and Saleh et al. (2017).

Table 2. Effect of artificial diet and natural preys on the immature stages of Coccinella undecimpunctata at $20^{\circ} \mathrm{C}$, $25^{\circ} \mathrm{C}$ and $30^{\circ} \mathrm{C}$ and $65 \pm 5 \% \mathrm{RH}$.

\begin{tabular}{lccccc}
\hline \multirow{2}{*}{ Type of diet } & Temp. & \multicolumn{4}{c}{ Duration periods } \\
\cline { 3 - 6 } & $\left.\mathbf{(}^{\mathbf{0}} \mathbf{C}\right)$ & Incubation period & Total larval stages & Pupal stage & Total immature stage \\
\hline \multirow{2}{*}{ Artificial diet } & 20 & $6.5 \pm 0.10 \mathrm{a}^{\mathrm{A}}$ & $22.9 \pm 0.16 \mathrm{a}^{\mathrm{A}}$ & $7.4 \pm 0.11 \mathrm{a}^{\mathrm{A}}$ & $36.7 \pm 0.19 \mathrm{a}^{\mathrm{A}}$ \\
& 25 & $5.7 \pm 0.09 \mathrm{~b}^{\mathrm{A}}$ & $21.5 \pm 0.12 \mathrm{~b}^{\mathrm{A}}$ & $6.0 \pm 0.08 \mathrm{~b}^{\mathrm{A}}$ & $33.2 \pm 0.19 \mathrm{~b}^{\mathrm{A}}$ \\
& 30 & $4.6 \pm 0.09 \mathrm{c}^{\mathrm{A}}$ & $17.7 \pm 0.12 \mathrm{c}^{\mathrm{A}}$ & $5.0 \pm 0.33 \mathrm{c}^{\mathrm{A}}$ & $27.5 \pm 0.15 \mathrm{c}^{\mathrm{A}}$ \\
\hline \multirow{2}{*}{ Ephestia kuhniella eggs } & 20 & $6.6 \pm 0.09 \mathrm{a}^{\mathrm{A}}$ & $19.2 \pm 0.18 \mathrm{a}^{\mathrm{B}}$ & $7.1 \pm 0.13 \mathrm{a}^{\mathrm{A}}$ & $33.0 \pm 0.25 \mathrm{a}^{\mathrm{B}}$ \\
& 25 & $5.7 \pm 0.09 \mathrm{~b}^{\mathrm{A}}$ & $15.9 \pm 0.12 \mathrm{~b}^{\mathrm{B}}$ & $5.7 \pm 0.09 \mathrm{~b}^{\mathrm{B}}$ & $27.2 \pm 0.18 \mathrm{~b}^{\mathrm{B}}$ \\
& 30 & $4.4 \pm 0.09 \mathrm{c}^{\mathrm{A}}$ & $13.5 \pm 0.17 \mathrm{c}^{\mathrm{B}}$ & $4.7 \pm 0.09 \mathrm{c}^{\mathrm{B}}$ & $22.7 \pm 0.20 \mathrm{c}^{\mathrm{B}}$ \\
\hline
\end{tabular}

Values followed by the same lowercase small letters in a column among temperatures within each diet and the same uppercase capital letters among diets in each temperature are not significantly different at the 5\% probability level (ANOVA, Student- Newan-Keuls Test).

\section{Survival rate:-}

Data presented in Table (3) indicated that, There were considerable variations survival percentage from egg to adult of C. undecimpunctata (at 20,25 and $30^{\circ} \mathrm{C}$ ) on E.kuhniella eggs and the artificial diet and the natural preys at $20^{\circ} \mathrm{C}(\mathrm{f}=$ $0.28, \mathrm{df}=2$ and $\mathrm{p}=0.7560)$, at $25^{\circ} \mathrm{C}(\mathrm{f}=4.77, \mathrm{df}=2$ and $\mathrm{p}=$ $\left.0.0109^{*}\right)$ and at $30^{\circ} \mathrm{C}(\mathrm{f}=4.91, \mathrm{df}=2$ and $\mathrm{p}=0.0096)$. While there were no significant differences between different temperatures under study when the artificial diet $(\mathrm{f}=1.13$, $\mathrm{df}=2$ and $\mathrm{p}=0.3265 \mathrm{~ns})$ and for E. kuhniella eggs $(\mathrm{f}=0.95$, $\mathrm{df}=2$ and $\mathrm{p}=0.3913 \mathrm{~ns}$ ). In Table (3), it can be noticed that the maximum value of larval survival percentage was $96.7 \%$ at $25^{\circ} \mathrm{C}$ on E. kuhniella eggs and $96.7 \%$ at 25 and $30{ }^{\circ} \mathrm{C}$ on $A$. gossypii and the minimum values were $73.3 \%$ at $30{ }^{\circ} \mathrm{C}$ on the artificial diet. And the maximum value total survival rate of the predator reared on the artificial diet was $83.33 \%$ at $20^{\circ} \mathrm{C}$, and $(96.67 \%$ and 96.67$)$ at $25^{\circ} \mathrm{C}$ on E. kuhniella eggs. These results are in agreement with those of El- Serafi, (2002) who reported that all immature stages of coccinellid predators showed

Significantly better response in acquiring the high survival rate and faster development when fed on live aphids sitobion avanae compared with artificial diet. Results indicate that the highest mortality rate was on the first and second instar of the larval stage it may be because of their thinner and softer cuticle. While the other larval instars and the pupal stage have a thicker cuticle protecting it from unsuitable abiotic condition similar results reported 
by Ponsonby and Copland (1996), Srivastava and Omkar (2003) and Said, 2018.

Table 3. The survival rate for larval instars and adult emergence percentage of the eleven- spotted ladybird $C$. undecimpunctata under laboratory conditions (20, 25 and $30 \pm 1^{\circ} \mathrm{C}$ and $65 \pm 5 \%$ R.H) when fed on natural preys and artificial diet

\begin{tabular}{lcccc}
\hline $\begin{array}{l}\text { Type of } \\
\text { nutrition }\end{array}$ & $\begin{array}{c}\text { Temp. } \\
\left({ }^{\mathbf{C}} \mathbf{C}\right)\end{array}$ & $\begin{array}{c}\text { Total larval } \\
\text { survival (\%) }\end{array}$ & $\begin{array}{c}\text { Emergency } \\
\text { rate (\%) }\end{array}$ & $\begin{array}{c}\text { Total survival } \\
\text { percentage }\end{array}$ \\
\hline Artificial & 20 & 83.3 & 92 & $83.33 \mathrm{a}^{\mathrm{A}}$ \\
diet & 25 & 80 & 95.8 & $76.67 \mathrm{a}^{\mathrm{B}}$ \\
& 30 & 73.3 & 90.9 & $66.67 \mathrm{a}^{\mathrm{B}}$ \\
\hline Ephestia & 20 & 90 & 96.3 & $86.67 \mathrm{a}^{\mathrm{A}}$ \\
kuhniella & 25 & 96.7 & 100 & $96.67 \mathrm{a}^{\mathrm{A}}$ \\
eggs & 30 & 93.3 & 96.4 & $90 \mathrm{a}^{\mathrm{A}}$ \\
\hline
\end{tabular}

Values followed by the same lowercase small letters in a column among temperatures within each diet and the same uppercase capital letters among diets in each temperature are not significantly different at the 5\% probability level (ANOVA, Student- Newan-Keuls Test).

\section{Longevity}

The obtained results arranged in Table (4) indicated that there were significant differences between the artificial diet and E. kuhniella eggs for the pre-oviposition period at $20 \pm 1^{\circ} \mathrm{C}\left(\mathrm{f}_{1,18}=12.8\right.$ and $\left.\mathrm{p}=0.0022^{* *}\right)$, at $25 \pm 1^{\circ} \mathrm{C}\left(\mathrm{f}_{1.18}\right.$ $=7.36$ and $\left.\mathrm{p}=0.0142^{*}\right)$ and at $30 \pm 1^{\circ} \mathrm{C}\left(\mathrm{f}_{1,18}=5.9\right.$ and $\mathrm{p}=$ $0.0258 *)$. And there were significant differences between the three temperature degrees were studied when $E$. kuhniella eggs $\left(\mathrm{f}_{2,27}=22.40\right.$ and $\left.\mathrm{p}=0.0000^{* * *}\right)$ and for the artificial diet $\left(\mathrm{f}_{1.18}=7.36\right.$ and $\left.\mathrm{p}=0.0142 *\right)$.

The obtained results arranged in Table (4) indicated that the preovipsition period at $30^{\circ} \mathrm{C} \pm 1$ and $65 \pm 5 \%$ R.H. was the shortest when females of C.undecimpunctata reared on E. kuhniella eggs and presented by $5.4 \pm 0.16$ days. While, the longest pre-ovipsition period when the predator females fed on the artificial diet and lasted $9.4 \pm 0.40$ days.

Oviposition period showed significant differences at $30 \pm 1^{\circ} \mathrm{C}$ for the three diets while significant differences between $E$. kuhniella eggs and the artificial diet at (20 and 25 $\left.\pm 1^{\circ} \mathrm{C}\right)$ when $E$. kuhniella eggs $\left(\mathrm{f}_{2,27}=4.92\right.$ and $\left.\mathrm{p}=0.0151^{*}\right)$ and for the artificial diet $\left(f_{2,27}=7.53\right.$ and $\left.p=0.0025^{* *}\right)$.

Regarding to the oviposition period recorded longest period were when the predator females reared on $E$. kuhniella eggs at $25 \pm 1^{\circ} \mathrm{C}$ and $65 \pm 5 \% \mathrm{RH}$ as compared to 20 and $30 \pm 1{ }^{\circ} \mathrm{C}$ and $65 \pm 5 \% \mathrm{RH}$, and lasted $53.4 \pm$ $0.37,50.9 \pm 1.49$ and $46.6 \pm 2.12$ days, respectively.

Data presented in Table (4) showed that when females reared on E. kuhniella eggs at $20 \pm 1^{\circ} \mathrm{C}$ and $65 \pm 5 \%$ $\mathrm{RH}$ gave the longest longevity and was $77.6 \pm 1.42$ days, while the lowest longevity was $62.9 \pm 1.19$ at $30 \pm 1^{\circ} \mathrm{C}$ and $65 \pm 5 \%$ RH when the female reared on the artificial diet.

Data in the Table (4) showed that significant differences between the artificial diet and E. kuhniella eggs for the female longevity when E. kuhniella eggs (f 2, $27=$ 22.40 and $\mathrm{p}=0.0000^{* * *}$ ) and for the artificial diet (f 2, $27=$ 10.00 and $\left.\mathrm{p}=0.0006^{* * *}\right)$. And male longevity when $E$. kuhniella eggs (f 2, $27=4.19$ and $\mathrm{p}=0.0259^{*}$ ) and for the artificial diet (f $2,27=7.16$ and $\mathrm{p}=0.0032^{* *}$ ). The results presented in Table (4) showed that when males reared on $E$. kuhniella eggs at $20 \pm 1{ }^{\circ} \mathrm{C}$ and $65 \pm 5 \% \mathrm{RH}$ gave the highest longevity and was $52.2 \pm 1.43$ days, while the lowest longevity observed when the male reared on the artificial diet at $25 \pm 1^{\circ} \mathrm{C}$ and $65 \pm 5 \% \mathrm{RH}$ and it was $42.9 \pm 1.36$ days.

Table 4. The adult longevity and fecundity of the ladybeetle $C$. undecimpunctata reared on artificial diets and natural preys three constant temperature degrees.

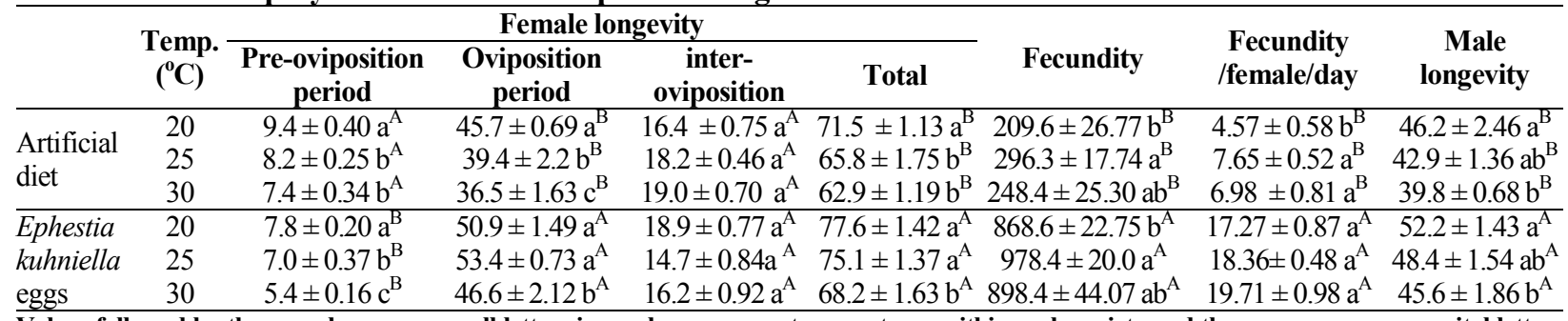

Values followed by the same lowercase small letters in a column among temperatures within each variety and the same uppercase capital letters among varieties in each temperature are not significantly different at the $5 \%$ probability level (ANOVA, Student- Newan-Keuls Test).

\section{Fecundity}

Significant differences were found for the fecundity percentage between the artificial diets and the natural preys at $\left(20\right.$ and $\left.25 \pm 1{ }^{\circ} \mathrm{C}\right)$, while under $30 \pm 1^{\circ} \mathrm{C}$ the results were not significant within each of artificial diet and E. kuhniella eggs as compared with 20 and $25 \pm 1^{\circ} \mathrm{C}$ for E. kuhniella eggs ( $f_{2,27}=3.38$ and $\mathrm{p}=0.0488^{*}$ ) and for the artificial $\operatorname{diet}\left(\mathrm{f}_{2,27}=3.39\right.$ and $\left.\mathrm{p}=0.0488^{*}\right)$.

High fecundity values were observed at $25 \pm 1{ }^{\circ} \mathrm{C}$ and $65 \pm 5 \% \mathrm{RH}$ for the different diets as compared to 20 and $30 \pm 1{ }^{\circ} \mathrm{C}$ and $65 \pm 5 \% \mathrm{RH}$ in general. On the other hand, the highest fecundity values was recorded when the female fed on E. kuhniella at $25 \pm 1{ }^{\circ} \mathrm{C}$ and it was $978.4 \pm 20.0$ eggs, While the fecundity values was low when the female reared on the artificial diet under $20 \pm 1{ }^{\circ} \mathrm{C}$ and $65 \pm 5 \% \mathrm{RH}$ and it was $209.6 \pm 26.77$ eggs. The increased fecundity with increase in temperature in ladybeetles was also reported in C. septempunctata, Adalia bipunctata ( Linnaeus), $H$. convergens, Coccinella undecimpunctata Linnaeus (Frazer and Mcgregor 1992), C. mntrouzieri (Jalali et a1. 1999) and Micrmpis discolor (Fabricius) (Omkar and Pervez 2002).

\section{REFERENCES}

Abdel-Salam, A. H. (1995). The biotic factors: Evaluation of their performance under natural conditions in cotton plantation. Ph. D. thesis, Fac. of Agric., Mansoura Univ., PP175.

Abdel-Salam, A. H. ; H. A. K. El-Serafi, ; M. H. Bayoumy and A. A. A. Abdel-Hady (2018). Effect of temperature and Aphid-Host plant variety on performance and thermal requirments of Coccinella undecimpunctata L. and Cheilomenes propinqua isis (mulsant). J. Plant Prot and Path., Mansoura Univ. 9(6): 375-380.

Babu, T. R., and K. M. Azam, (1987). Biology of Cryptolaemus montrouzieri Mulsant [Coccinellidae: Coleoptera] in relation with temperature. Entomophaga, 32(4): 381-386. 
Bahy El-Din, I. H. (2014), Biological control of aphids by utilization of some coccinellid species. Ph. D. thesis. Fac. of agric. Moshtohor Banha University. PP.163.

Bayoumy, M. H.; A. M. Abou-Elnaga; A. A. Ghanim and GH. A. Mashhoot (2015). Biological characteristics and heat requirements for Coccinella undecimpunctata - Sitobion avanae and Coccinella 9-punctata - Aphis craccivora feeding systems at varying temperature regimes. J. Plant prot. And path., Mansoura univ. 6(7): 1049-1065.

Chen, Z. H. and Qin, J. (1982): The nutritional role of water content in the artificial diet of Coccinella septumpunctata L. Acta Entomologic Sinica 25: 141146.

Dreistadt, S. H. and U. C. Statewide (2014). Biological control and natural enemies of invertebrates. Univ. Calif. 1-6.

El-Heneidy, A. H. ; A. A. Hafez ; F. F. Shalaby and I. A. ELDin (2008). Compertative biological aspects of the two coccinellid species; Coccinella undecimpunctata L. and Hippodamia convergens Guer. under laboratory conditions. Egypt. J. Biol. Pest Control 18(1): 51-59.

El-Serafi, H., A. K.; A. H. Abdel-Salam and A. A. Ghanim (2002). Evaluation of longevity, feeding capacity, and fecundity of certain coccinellid predatory insects reared on an artificial diet and natural prey under laboratory conditions. $2^{\text {nd }}$ interational conference, plant protection research institute, Cairo, Egypt, 21-24 December, 2002.

Frazer, B. D., and R. R. McGregor, (1992). Temperaturedependent survival and hatching rate of eggs of seven species of Coccinellidae. Can. Entomol., 124(2): 305312.

Ghanim, A. A. and M. A. El-Adl (1987). Evaluation of predation activity and fecundity of the coccinellids, Cydonia (Chilomenes) vicina isis $\mathrm{Cr}$., Cydonia vicina nilotica Muls. and Coccinella undecimpunctata L. Mansoura region. Egyptian Journal of Agricultural Science, 12, 993-1000.

Ghanim, A. A. and M. A. EL-Adl (1996). Mass rearing of certain coccinellid predators insects on and the bases of mixing holidic and meridic methods. J. Agric. Sci. Mansoura Univ. 21(9): 3341- 3349.

Ghanim, A. A. and M.A. EL-Adl (1997), Evaluation of certain artificial diets for mass rearing of some coccinellid predatory insects. First National Conf. of Applied Using of Natural Enemies for Controlling Insects and Mite Pests, Mansoura, 191- 198.

Ghanim, A. A.; H. A. El- Serafi and M.A. EL-Adl (2000), development of artificial diets for the rearing of cooccinellid predatory. J. Agric. sci. Mansoura University, 25(12): 8197- 8203.
Hattingh, V. and M. j. samways (1993). Evaluation of artificial diets and two species of natural prey as laboratory food for Chilocorus spp. Entomol. exp. appl. 69: 13-20.

Hodek I. ; H. F. van Emden and A. Honek (2012). Ecology and behaviour of the ladybird beetles (Coccinellidae). Wiley-Blackwell, Chichester. 1-561.

Jalali, S. K. ; Singh, S. P., and S. R. Biswas, (1999). Effect of temperature and female age on the development and progeny production of Cryptolaemus montrouzieri Mulsant (Coleoptera: Coccinellidae). Entomon., 24(3): 293-296.

Khan M. R. and M. R. Khan (2010). The Relationship Between Temperature and the Functional Response of Coccinella septempunctata L. (Coleoptera: Coccinellidae). Pakistan J. Zool., 42(4), 461-466.

L. A. El-Batran; A. A. Ghanim; L. M. Shanab and M. M. Ramadan (2015). Thermal requirements for development of Aphis nerii Boyer de fonscolombe and its predator Cydonia vicina isis Muls. J. Plant Prot and Path., Mansoura Univ. 6(5): 825-837.

Mohamed, N.E. (2013). Effect of constant temperature degrees on certain biological characterstics of the coccinelld predator Rodalia cardinalis (mulsant) (coleoptera: coccinellidae). J. Plant Prot. and Path., Mansoura Univ., 4(10):845-855.

Mohamed, N., E. (2001), mass- rearing of certain predatory insects on artificial diets for controlling some insects infesting vegetable crops. Ph. D. Thesis. Fac. of agric. Mansoura Univ. PP. 93.

Okada, I. (1970). A new method of artificial rearing of a coccinellid beetle, Harmonia axyridis Pallas as Heredity, Tokyo 24: 32-35.

Pervez, A. and K. G. omkar (2002). Influence of temperature on age-specific fecundity of the ladybeetle Micraspis discolor (Fabricius). Int. J. of Insect Sci., 22(1): 61-65.

Ponsonby, D. J. and M. J. W. Copland (1996). Effect of temperature on development and immature survival in the scale insect predator, Chilocorn nigritus ( F .) ( Coleoptera : Coccinellidae ). Biocontrol Sci. \& Tech. 6: 101-109.

Said, A., A. A. (2018). Tri- trophic interactions among certain plant cultivars. Aphid species and their insect predators. Ph. D. Thesis. Fac. of agric. Mansoura Univ. PP. 163.

Song, F., and S. M. Swinton, (2009). Returns to integrated pest management research and outreach for soybean aphid. Journal of economic entomology, 102(6): 2116-2125.

Srivastava, S. and K. G. Omkar (2003). Influence of temperature on certain biological attributes of a ladybeetle Coccinella septempunctata Linnaeus. Insect Sci., 10 (3): 185-193.

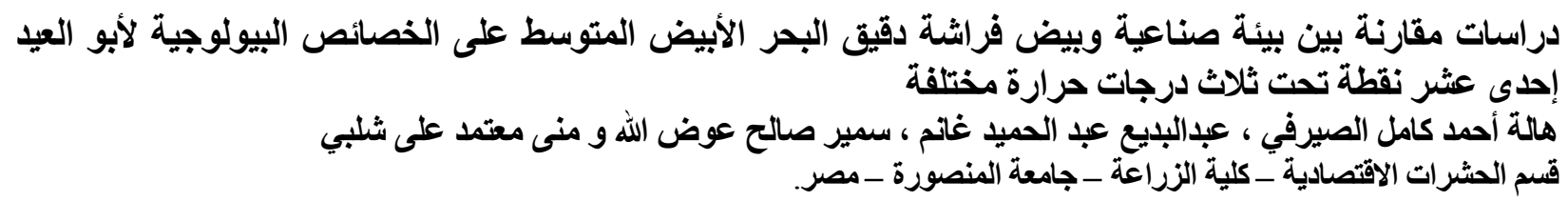

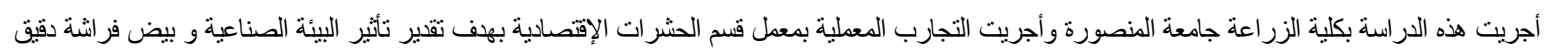

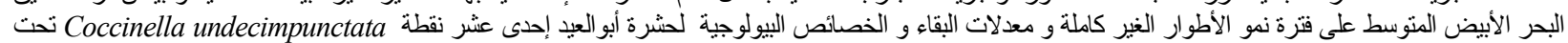

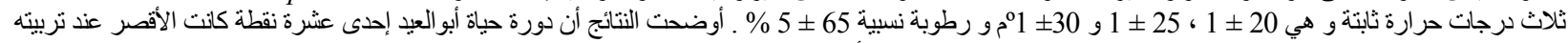

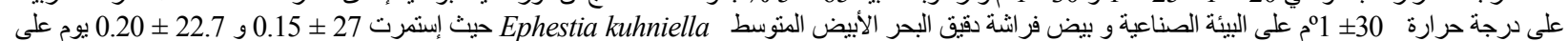

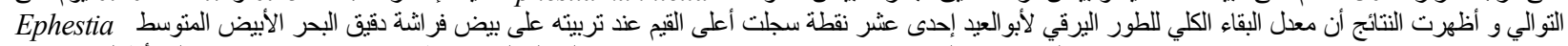
96hniella

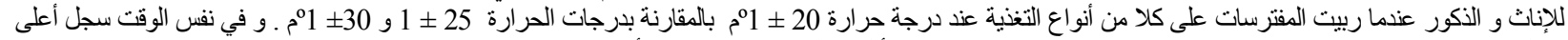

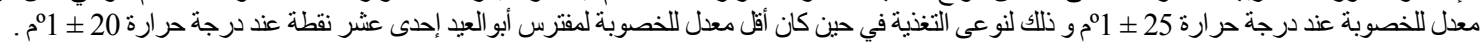

